\title{
Student Performance and Perception Regarding Descriptive and Case Based Anatomy Questions
}

\author{
H. A. Amaratunga ${ }^{1}$, S. P. M. Peiris ${ }^{2}$, H. R. Gunasena ${ }^{1}$
}

\begin{abstract}
Objective: It was the objective of this study to quantify the performance and ascertain the first year students' perception of descriptive and clinical anatomy questions.

Methods: Students in the $1^{\text {st }}$ year $2^{\text {nd }}$ semester at the Faculty of Medicine Peradeniya were recruited. They were given 2 questions similar to exam questions from a familiar area. One question was descriptive, and the other a clinical case scenario. Students were given 30 minutes to answer. Scripts were marked according to a marking scheme and scored out of hundred. At the end of the assessment students were given a questionnaire to gather information regarding their perception regarding the two types of questions.

Results: There were 192 students and all had answered both questions. Average scores were $73.2 \%$ for the descriptive question and $65.7 \%$ for the clinical case scenario. Of the students $65.3 \%$ thought that the clinical case scenario type of question should be given for assessments while $58 \%$ said that they preferred to answer this type of question. Eighty two percent said descriptive type of question was easy.
\end{abstract}

Conclusion: It is evident from these findings that even though students score better in descriptive type of questions a majority think that clinical case based questions should be included in assessment and they prefer to answer such questions.

Key words: student performance, student perception, anatomy examinations.

\section{INTRODUCTION}

Anatomy is largely a descriptive science. However when it comes to teaching anatomy to medical students, teaching pure anatomy as a descriptive science has lost its usefulness. Therefore some anatomy curricular have included clinical case based anatomy teaching (1). Although the descriptive aspect of anatomy has to be taught in the initial stages, where students have to learn the basics of the structure of organs, the clinical aspects to bring out the importance of learning basic sciences at an early stage $(2,3)$. This makes a rather boring subject much more interesting and 
AMAratungA, H. A., PeIRIS, S. P. M., GUNASENA, H. R., Student performance and perception regarding descriptive and case based Anatomy questions. Sri Lanka Anatomy Journal (SLAJ), 1(1): 2- 5, 2017.

applicable to the students' future learning years.

A debate exists between different groups as to which aspect should be assessed at exams. While certain groups stressed the importance of asking questions related to clinical knowledge, while others stressed that questions should focus more on descriptions of structures. It has been observed that students find descriptive types of questions much easier and they score more marks for such questions while questions based on clinical scenarios tend to be more difficult (perscomm). The objective of this study was to ascertain the first year students' perception of these different types of questions and to quantify the performance in each style of question.

\section{METHODS}

Students in the $1^{\text {st }}$ year $2^{\text {nd }}$ semesters at the Faculty of Medicine were recruited for the study. Participation was completely voluntary and no data was collected on those who refused to participate. The students were given a question paper that consisted of 2 different types of anatomy questions similar to the ones given during examinations and tutorials. The first question was a description of a structure where students had to describe the structure in detail, while the $2^{\text {nd }}$ was a clinical case scenario where the students had to discuss the anatomical basis of a disease condition. The questions were given from an area which they had already studied.

Students were given 30 minutes to answer the two questions. Answer scripts were collected and marked by the principal investigator according to a predesigned marking scheme. Each student was given a score out of hundred. At the end of this session students were asked 3 questions regarding the two different types of questions that they had answered. The questions were; which type they thought was easy, which type they thought should be included in the assessments and which type they preferred to answer. They were also asked for, reasons for each preference.

\section{RESULTS}

All students in the batch present on the day of the study consented to participate. There were 192 students in the sample. All students had answered both questions. It was observed that the students had scored the high percentage of marks (73.4\%) for the descriptive type of question and the lower percentage of marks for the clinical case scenario $(65.7 \%)$ and there was a statistically significant difference between the two mean scores (Figure 1). It was interesting to see that $65.3 \%$ of students thought that the clinical case scenario type of question should be given for assessments while the rest were of the 
AMAratungA, H. A., PeIRIS, S. P. M., GUNASENA, H. R., Student performance and perception regarding descriptive and case based Anatomy questions. Sri Lanka Anatomy Journal (SLAJ), 1(1): 2- 5, 2017.

opinion that descriptive type of questions should be included. The difference in the proportions was statistically significant. Of the students $58 \%$ said that they preferred to answer clinical case based type of question while $42 \%$ preferred the descriptive type (Figure 2). Here too the difference was statistically significant.

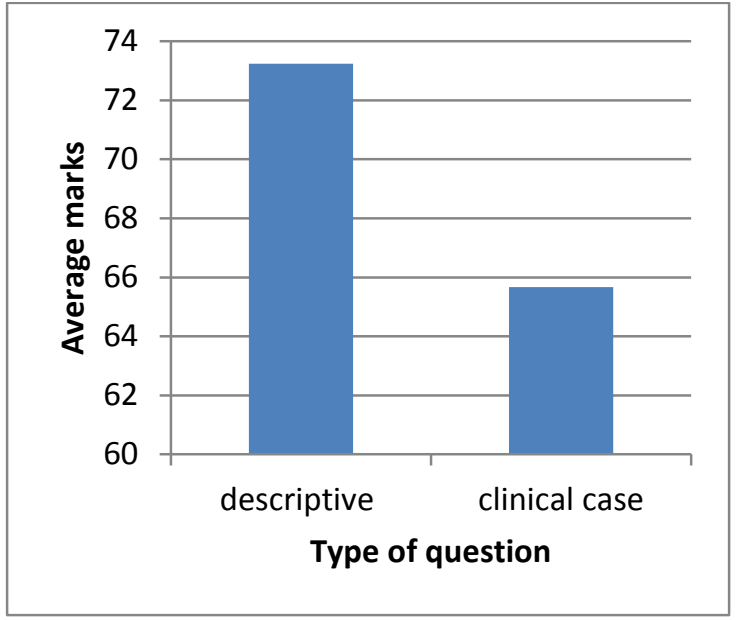

Figure 1. Average marks for each question $(\mathrm{n}=192)$

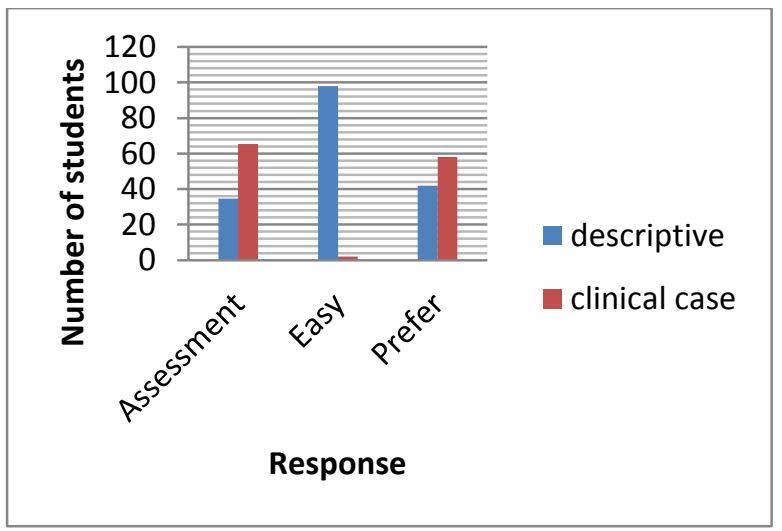

Figure 2. Student perception of the two different types of questions

\section{DISCUSSION}

Anatomy is mostly described as a basic science which is necessary for clinical practice $(4,5)$. Students generally think that Anatomy is a subject which necessitates memorization of subject matter and reproduction of the same in the examination setting (6). However anatomy education is moving away from this traditional methods towards problem based curriculum with some resistance (7). With the change in curricula towards a more clinically orientated teaching method assessment needs to change parallel to this change. We designed our study in order to assess student performance and perception of clinical case based and descriptive type of questions.

As expected a majority of students scored highest marks in the descriptive type of question, while they scored less for the clinical cases. It was interesting to see that even though the students as an average had scored fewer marks for the clinical cases question, the majority thought this type of questions should be given for assessments. When asked why they thought so, the reasons a majority of them had stated was that they thought it would help them in their future years and also that such questions were much more interesting and challenging.

It is evident from these findings that even though students score better in descriptive 
AMAratungA, H. A., PeIRIS, S. P. M., GUNASENA, H. R., Student performance and perception regarding descriptive and case based Anatomy questions. Sri Lanka Anatomy Journal (SLAJ), 1(1): 2- 5, 2017.

type of questions a majority think that

clinical case based questions should be included in assessment and they prefer to answer such questions.

\section{REFERENCES}

1. Johnson EO, Charchanti AV, Troupis TG. Modernization of an anatomy class: From conceptualization to implementation. A case for integrated multimodalmultidisciplinary teaching. Ana ScieEdu 2012; 5:354-366.

2. Bethe A. Kritische, Betrachtungenu"ber den vorklinischenUnterricht. [Critical observations on preclinical education].KlinischeWochenschrift 1928; 7:1481-1483.

3. Anderson J. The continuum of medical education: The role of basic medical sciences. J R Col of Physicians Lond1980; 27: 405-407.

4. Drake R. Meeting the challenge: the future of the anatomical sciences in medical school curricula. Anat Rec 2002;269:68.

5. Drake R, Lowrie D, Prewitt C. Survey of gross anatomy, microscopic anatomy, neuroscience, and embryology courses in medical school curricula in the United States. Anat Rec (New Anat), 2002;269: 118-122.

6. Miller SA, Perrotti W, Silverthorn DU, Dalley AF, Rarey KE. From college to clinic: reasoning over memorization is key for understanding anatomy. Anat Rec 2002;269: 69-80.

7. Colliver JA. Effectiveness of problembased learning curricula: research and theory. Acad Med 2000;75: 259-266.

\section{CORRESPONDENCE:}

Dr. H. A. Amaratunga,

Department of Anatomy,

Faculty of Medicine,

University of Peradeniya, Sri Lanka.

Email-himanipeiris@yahoo.com,

Received: May 2017

Accepted: July 2017 